\title{
Chemistry in Low Pressure Cold Plasmas: Ions of Astrophysical Interest
}

\author{
E. Carrasco, M. Jiménez-Redondo, I. Tanarro and V. J. Herrero* \\ Instituto de Estructura de la Materia, IEM-CSIC, Serrano 123, 28006 Madrid, Spain \\ E-mail: v.herrero@csic.es
}

\begin{abstract}
The ionic chemistry of various hydrogen mixtures $\left(\mathrm{H}_{2} / \mathrm{N}_{2}, \mathrm{H}_{2} / \mathrm{O}_{2}\right.$, and $\mathrm{H}_{2} /$ air $)$ has been studied in low pressure hollow cathode discharges. The major ions identified in the different discharges $\left(\mathrm{H}_{3}{ }^{+}, \mathrm{N}_{2} \mathrm{H}^{+}, \mathrm{H}_{3} \mathrm{O}^{+}\right.$and $\left.\mathrm{NH}_{4}{ }^{+}\right)$have been also found in astronomical observations or predicted in astrochemical models. The relative stability of the protonated ions in the various mixtures has been investigated in detail. In discharges of $\mathrm{H}_{2}$ with small amounts of $\mathrm{N}_{2}, \mathrm{O}_{2}$ and air, appreciable amounts of $\mathrm{NH}_{3}$ and $\mathrm{H}_{2} \mathrm{O}$ were formed at the reactor walls. The preponderance of the protonated ions in these plasmas was found to be largely dictated by the proton affinity of their respective molecular precursors. Even for small amounts of water and ammonia, proton transfer reactions tend to concentrate the positive charge in $\mathrm{H}_{3} \mathrm{O}^{+}$and, specially, in $\mathrm{NH}_{4}{ }^{+}$ions. These results support the predictions of some astrochemical models indicating that these ions could be dominant in warm astronomical environments where $\mathrm{H}_{2} \mathrm{O}$ and $\mathrm{NH}_{3}$ molecules evaporate from dust grain mantels.
\end{abstract}

\section{Introduction}

Cold plasmas produced in low pressure glow discharges find widespread application in many fields of science and technology. They are variously used in material processing [1-4], elemental analysis [5], sterilization [6], or in controlled fusion devices, where they are employed for wall conditioning and cleaning [7-9]. These plasmas provide highly reactive media at low gas temperatures and densities [10,11]. Reactive species (radicals, ions, excited atoms and molecules) are primarily produced in the collisions of stable molecules with the light plasma electrons, which have typical temperatures in the $1-10 \mathrm{eV}$ range. For the characteristic low pressures of this type of discharges, the small collision frequency may limit the contribution of the gas-phase to the overall neutral chemistry, which can be often dominated by surface processes. In contrast, ionic chemistry is restricted to the gas phase. Ion-molecule reactions have large cross sections and are efficient even with few collisions and, in addition, the reactor walls act as an effective sink for the ions, which are neutralized upon impact. Due to these characteristics, cold plasmas of suitable precursors offer also a good opportunity for the generation and study of ions of interest in planetary ionospheres, cometary tails, or interstellar space. 
The concentrations of ions in interstellar space are many orders of magnitude lower than that of $\mathrm{H}_{2}$, which is the most abundant molecule. However, due to the fact that ion-molecule reactions are often barrierless and have large cross sections, ions are assumed to be decisive in the low temperature gas-phase chemistry of the interstellar medium (ISM) [12-14]. At present, about 20 cations and 6 anions have been identified in astronomical observations of the ISM (see $[15,16]$ and references therein). Many of the cations are protonated derivatives of small molecules. The initiator of the protonation chain is the $\mathrm{H}_{3}{ }^{+}$ion, which is the most abundantly produced interstellar species, next only to $\mathrm{H}_{2}$ [17]. Protonated hydrogen is very efficiently formed in collisions of $\mathrm{H}_{2}$ with $\mathrm{H}_{2}{ }^{+}$, which is in turn generated via cosmic ray ionization. This symmetric triatomic ion lacks a permanent dipole moment and was first detected in the ISM using infrared spectroscopy [18]. The $\mathrm{H}_{3}{ }^{+}$ion has a relatively low proton affinity and tends to transfer its proton and revert to $\mathrm{H}_{2}$ upon collision with most molecules. In fact, proton transfer chains are at the root of much of the ion-molecule chemistry in dense interstellar clouds ${ }^{13,15,17}$. In low temperature environments like dense molecular clouds, $\mathrm{HCO}^{+}$and $\mathrm{N}_{2} \mathrm{H}^{+}$, the protonated species of $\mathrm{CO}$ and $\mathrm{N}_{2}$, are observed among others [15,19], but the more polar and thus less volatile molecules like $\mathrm{H}_{2} \mathrm{O}, \mathrm{NH}_{3}$ or $\mathrm{CH}_{3} \mathrm{OH}$ remain largely frozen on the surface of dust grains and do not contribute appreciably to the gas-phase chemistry. Collisions of $\mathrm{H}_{3}{ }^{+}$with $\mathrm{HD}$ start a chain of reactions leading to the stepwise formation of $\mathrm{H}_{2} \mathrm{D}^{+}, \mathrm{D}_{2} \mathrm{H}^{+}$, and $\mathrm{D}_{3}{ }^{+}$. The sequence is dictated by the lower zero point energy (ZPE) of the heavier species, which are thought to cause the large deuterium enrichment observed for many molecules in cold interstellar media [20]. This D enhancement can be orders of magnitude higher than the cosmic $\mathrm{D} / \mathrm{H}$ ratio of $\sim 10^{-5}$. As pointed out by Oka [17], the occurrence of the $\mathrm{H}_{3}{ }^{+}$ion is not limited to cold interstellar regions. In principle, given the ubiquity of cosmic rays, $\mathrm{H}_{3}{ }^{+}$should be abundantly produced in any region with molecular $\mathrm{H}_{2}$. However, the ZPE effects leading to a selective increase in deuteration decrease markedly with growing temperature $[21,22]$.

In warmer media like hot cores, photon dominated regions or active galactic nuclei, temperatures rise beyond $100 \mathrm{~K}$ and can be even much higher. The high temperature chemistry of these warmer regions is expected to differ in many respects from that of the cold molecular clouds [23]. From the specific point of view of ion chemistry, the grain desorption of $\mathrm{H}_{2} \mathrm{O}$ and $\mathrm{NH}_{3}$ releases to the medium two species with high proton affinities, which should tend to prevail in protonation chains. In fact, in spite of the relatively small fraction of $\mathrm{H}_{2} \mathrm{O}$ and $\mathrm{NH}_{3}$ as compared with other interstellar species, astrochemical models predict their protonated derivatives, $\mathrm{H}_{3} \mathrm{O}^{+}$and $\mathrm{NH}_{4}{ }_{4}$, to dominate the ion distributions in some warm environments [23$25]$.

In this work, we present a comparative study of room temperature ion chemistry in hollow cathode (HC) direct current (DC) discharges of $\mathrm{H}_{2} / \mathrm{N}_{2}, \mathrm{H}_{2} / \mathrm{O}_{2}$ and $\mathrm{H}_{2} /$ air. The study builds on 
our previous experimental investigation and modelling of $\mathrm{H}_{2} / \mathrm{N}_{2}$ discharges [26], and incorporates new data on $\mathrm{H}_{2} / \mathrm{O}_{2}$ and $\mathrm{H}_{2}$ /air plasmas. In our choice of representative species for the experiments we have avoided the introduction of carbon containing molecules to the reactor in order to maintain the stability of the discharge. Carbon containing species undergo a complex wall chemistry resulting in the formation of layers at the reactor surfaces that cause unwanted perturbations of the discharge and hamper the study of the ion-molecule processes we are interested in. However, as we will discuss below, the main conclusions can be arguably extended to most small gas-phase molecules common in the ISM.

The focus is set on the production and interconversion of the astrophysically relevant protonated ions mentioned in the previous paragraphs. The present research has been carried out on low pressure weakly ionized plasmas dominated by $\mathrm{H}_{2}$, where the ion distributions are determined by binary ion-molecule collisions. These characteristics resemble qualitatively (but certainly do not match) those found in some interstellar media, and the results are discussed in the light of this similitude.

\section{Experimental}

The experimental set-up for the present measurements has been described in detail in previous publications [22,27-28]. Plasmas of various gas mixtures $\left(\mathrm{H}_{2} / \mathrm{N}_{2}, \mathrm{H}_{2} / \mathrm{O}_{2}\right.$ and $\mathrm{H}_{2} /$ air $)$ in variable proportions, but with a $\mathrm{H}_{2}$ relative concentration always larger than $80 \%$, are produced in DC discharges inside a grounded cylindrical stainless steel chamber $(30 \mathrm{~cm}$ height $\mathrm{x} 10 \mathrm{~cm}$ diameter) acting as a hollow cathode and provided with a central anode. The $\mathrm{HC}$ arrangement provides a large and homogeneous glow region with an electric field value close to zero, especially well suited for spectroscopic and kinetic studies. The reactor, which is pumped to a base pressure of $10^{-4} \mathrm{~Pa}$ by a $4501 \mathrm{~s}^{-1}$ turbomolecular pump and a dry pump, has several ports for the admittance of the fuel gases, for pressure gauges, and for coupling to the diagnosis techniques, namely, mass spectrometry of neutrals and ions, and double Langmuir probes for the measurement of electron temperatures and densities [29]. The quadrupole mass spectrometers (QMS) for neutrals (Balzers QMS200) and ions (Balzers PPM422) are located in differentially pumped vacuum chambers and connected to the reactor through $100 \mu \mathrm{m}$ diaphragms. For the detection of neutrals, the molecules reaching the detector are ionized through electron bombardment, and then an ionic fragment with a suitable mass/charge ratio is selected for each of the species of interest ( 2 for $\mathrm{H}_{2}, 16$ for $\mathrm{NH}_{3}, 18$ for $\mathrm{H}_{2} \mathrm{O}, 28$ for $\mathrm{N}_{2}$, and 32 for $\mathrm{O}_{2}$ ). Only stable neutral molecules are detected this way. The plasma ions are directly extracted from the discharges through the sampling orifice of the ion detector and are mass analyzed. Typical pressures in the detector chambers during operation are in the $10^{-5} \mathrm{~Pa}$ range. 
The measurements were performed under continuous flow conditions by balancing the entrance gas flow, regulated with needle valves, with the total exit flow, controlled with a gate valve at the end of the reactor. Total pressures in the reactor were measured with a capacitance manometer (Leybold CTR90). The discharges were found to be stable in the $\sim 0.8-20$ Pa range. For the present measurements, a total pressure of $8 \mathrm{~Pa}$ was selected. This value was found to be particularly appropriate for the investigation of ion-molecule chemistry [22,26]. The proportion of the two gases before the ignition of the discharge was set with the aid of the QMS200 mass spectrometer, whose efficiency for the measurement of the various stable molecules had been previously calibrated. The residence time of the gases in the chamber was $\sim 0.75 \pm 0.15 \mathrm{~s}$. Plasma currents of $150 \mathrm{~mA}$ and supplied voltages of $\sim 400 \mathrm{~V}$ were sustained during the experiments. In the resulting cold plasmas, gas temperatures for the neutral species were about $300 \mathrm{~K}[29,30]$ and the temperatures of positive ions are assumed to be similar or slightly higher. Electron temperatures, $\mathrm{T}_{\mathrm{e}}$, and densities, $\mathrm{N}_{\mathrm{e}}$, were determined with the Langmuir probe. The range of $T_{e}$ and $\mathrm{N}_{\mathrm{e}}$ values for the various mixtures studied were $2.5-4 \mathrm{eV}$ and $2-3 \times 10^{10} \mathrm{~cm}^{-3}$ respectively. Individual ion densities in the plasma were derived from the ion fluxes recorded with the PPM422 mass spectrometer. It is worth noting that the total concentrations of neutrals $\left(\sim 10^{15} \mathrm{~cm}^{-3}\right)$ are several orders of magnitude larger than those of ions $\left(\sim 10^{10} \mathrm{~cm}^{-3}\right)$ in all the discharges studied.

\section{Results and discussion}

In our $\mathrm{HC}$ reactor, the ion distributions of plasmas of pure $\mathrm{H}_{2}$ at $8 \mathrm{~Pa}$ are dominated by triatomic $\mathrm{H}_{3}{ }^{+}$ions [28] produced in the reaction:

$$
\mathrm{H}_{2}^{+}+\mathrm{H}_{2} \rightarrow \mathrm{H}_{3}^{+}+\mathrm{H} \quad\left(\mathrm{k}=2.00 \times 10^{-9} \mathrm{~cm}^{3} \mathrm{~s}^{-1}\right)
$$

The high value of the rate coefficient indicates that virtually any collision of $\mathrm{H}_{2}^{+}$with $\mathrm{H}_{2}$ will lead to the transfer of one proton. Unless otherwise stated, all the rate coefficients cited in this work are taken from [31]. In mixtures of $\mathrm{H}_{2} / \mathrm{D}_{2}$ the triatomic species $\mathrm{H}_{3}{ }^{+}, \mathrm{H}_{2} \mathrm{D}^{+}, \mathrm{D}_{2} \mathrm{H}^{+}$and $\mathrm{D}_{3}{ }^{+}$in variable proportions are also found to dominate the ion distributions [22]. In general, the mixed ions $\mathrm{H}_{2} \mathrm{D}^{+}$and $\mathrm{D}_{2} \mathrm{H}^{+}$are favoured, as expected on statistical grounds. Not surprisingly, only a residual influence of the ZPE bias towards higher deuteration [20] is predicted in model simulations of our room temperature plasmas, but these small effects lie within our experimental uncertainty. More marked isotope selectivity, leading to the preferential formation of $\mathrm{H}^{+}$over $\mathrm{D}^{+}$, is found in the ion chemistry of our discharges [22], but the processes involved are probably unimportant for deuterium fractionation in space.

When small amounts of other species are introduced to the hydrogen discharges, $\mathrm{H}_{3}{ }^{+}$ions are largely removed. Figure 1 shows the evolution of the relative concentrations of neutrals and 
protonated ions in $\mathrm{H}_{2} / \mathrm{N}_{2}$ plasmas as a function of the initial $\mathrm{N}_{2}$ concentration. Although other ions also form in the discharges to be discussed in this section, protonated species are always dominant and we will restrict our attention to them. As discussed elsewhere [26], a small but appreciable amount of $\mathrm{NH}_{3}$ forms at the reactor walls. The concentration of ammonia increases monotonically, roughly in parallel with that of $\mathrm{N}_{2}$. The ion distributions are rather different from those of their neutral precursors. The $\mathrm{H}_{3}{ }^{+}$ion, formed in reaction 1 , dominates the ion distribution only for the lowest $(<2 \%) \mathrm{N}_{2}$ fractions; beyond this point, $\mathrm{N}_{2} \mathrm{H}^{+}$and $\mathrm{NH}_{4}^{+}$grow at the expense of $\mathrm{H}_{3}{ }^{+}$and, with further increase in the amount of $\mathrm{N}_{2}$ (and thus in the $\mathrm{NH}_{3}$ concentration), $\mathrm{NH}_{4}{ }^{+}$becomes prevalent. As indicated above, the low proton affinity of $\mathrm{H}_{2}$ is responsible for the marked decrease in the relative concentration $\mathrm{H}_{3}{ }^{+}$, which acts as a proton donor for most molecules. Table 1 lists the proton affinities of the molecules considered in this study.

\begin{tabular}{|l|l|}
\hline Molecule & Proton affinity ${ }^{\mathrm{a}}\left(\mathrm{kJ} \mathrm{mol}^{-1}\right)$ \\
\hline $\mathrm{H}_{2}$ & 422.3 \\
\hline $\mathrm{N}_{2}$ & 493.8 \\
\hline $\mathrm{O}_{2}$ & 421.0 \\
\hline $\mathrm{NH}_{3}$ & 853.6 \\
\hline $\mathrm{H}_{2} \mathrm{O}$ & 691.0 \\
\hline
\end{tabular}

a) From reference [32]

As can be seen, both $\mathrm{N}_{2}$ and $\mathrm{NH}_{3}$ have larger proton affinities than $\mathrm{H}_{2}$. These ions are formed in the plasmas preferentially through reactions:

$$
\begin{array}{ll}
\mathrm{H}_{3}{ }^{+}+\mathrm{N}_{2} \rightarrow \mathrm{N}_{2} \mathrm{H}^{+}+\mathrm{H}_{2} & \left(\mathrm{k}=1.86 \times 10^{-9} \mathrm{~cm}^{3} \mathrm{~s}^{-1}\right) \\
\mathrm{H}_{3}{ }^{+}+\mathrm{NH}_{3} \rightarrow \mathrm{NH}_{4}{ }^{+}+\mathrm{H}_{2} & \left(\mathrm{k}=4.40 \times 10^{-9} \mathrm{~cm}^{3} \mathrm{~s}^{-1}\right)
\end{array}
$$

A preliminary analysis based on a kinetic model of the plasma [26] shows that the predominance of $\mathrm{NH}_{4}{ }^{+}$for the highest $\mathrm{N}_{2}$ fractions is mainly due to the reaction:

$$
\mathrm{N}_{2} \mathrm{H}^{+}+\mathrm{NH}_{3} \rightarrow \mathrm{NH}_{4}^{+}+\mathrm{N}_{2} \quad\left(\mathrm{k}=2.3 \times 10^{-9} \mathrm{~cm}^{3} \mathrm{~s}^{-1}\right)
$$

This reaction becomes relevant when the $\mathrm{NH}_{3}$ density in the plasma allows for collisions between this molecule and $\mathrm{N}_{2} \mathrm{H}^{+}$before the ion leaves the plasma and is neutralized at the 
cathode wall. Again in this case, the hierarchy of proton affinities (see Table 1) determines the direction of the proton transfer. Although the key reactions 2 - 4 provide a simple rationale for the observed ion distributions, the actual ion chemistry in these plasmas is much more complex, as discussed in [26].

The evolution of neutrals and protonated ions in $\mathrm{H}_{2} / \mathrm{O}_{2}$ discharges is displayed in Figure 2. In this case, wall reactions lead to an efficient production of $\mathrm{H}_{2} \mathrm{O}$, whose concentration in the steady-state plasma surpasses that of the $\mathrm{O}_{2}$ fuel gas. This is in contrast to the behaviour observed for $\mathrm{H}_{2} / \mathrm{N}_{2}$ discharges, where $\mathrm{N}_{2}$ was always more abundant than $\mathrm{NH}_{3}$. Although a model is not available for these mixtures, the main findings can be tentatively explained with simple considerations based on the most likely chemical mechanisms. Given the comparatively high amount of water $\left(>1 \%\right.$ ) formed even for the lowest $\mathrm{O}_{2}$ fraction studied, $\mathrm{H}_{3} \mathrm{O}^{+}$is always dominant in the ion distributions. Hydronium is mainly formed in the reaction:

$$
\mathrm{H}_{3}{ }^{+}+\mathrm{H}_{2} \mathrm{O} \rightarrow \mathrm{H}_{3} \mathrm{O}^{+}+\mathrm{H}_{2} \quad\left(\mathrm{k}=5.3 \times 10^{-9} \mathrm{~cm}^{3} \mathrm{~s}^{-1}\right)
$$

In contrast with the results for the analogous $\mathrm{H}_{2} / \mathrm{N}_{2}$ discharges, where $\mathrm{N}_{2} \mathrm{H}^{+}$was abundant, only a tiny amount of $\mathrm{HO}_{2}{ }^{+}$was found in the $\mathrm{H}_{2} / \mathrm{O}_{2}$ plasmas. The reason lies again in the relative proton affinities of their relevant neutral precursors. Table 1 shows that the proton affinity of $\mathrm{O}_{2}$ is comparable (but slightly smaller) to that of $\mathrm{H}_{2}$, consequently the proton transfer from $\mathrm{H}_{3}{ }^{+}$to $\mathrm{O}_{2}$ is not much favoured. This is also reflected in the values of the room temperature coefficients for the forward and reverse protonation reactions:

$$
\begin{array}{ll}
\mathrm{H}_{3}{ }^{+}+\mathrm{O}_{2} \rightarrow \mathrm{HO}_{2}^{+}+\mathrm{H}_{2} & \left(\mathrm{k}=6.70 \times 10^{-10} \mathrm{~cm}^{3} \mathrm{~s}^{-1}\right) \\
\mathrm{HO}_{2}{ }^{+}+\mathrm{H}_{2} \rightarrow \mathrm{H}_{3}{ }^{+}+\mathrm{O}_{2} & \left(\mathrm{k}=3.30 \times 10^{-10} \mathrm{~cm}^{3} \mathrm{~s}^{-1}\right)
\end{array}
$$

In the reactions commented on previously, with rate coefficients in the $10^{-9} \mathrm{~cm}^{3} \mathrm{~s}^{-1}$, the reverse processes were negligible [31]. In this case, however, the rate coefficients are smaller and more comparable, and the production of $\mathrm{HO}_{2}^{+}$via reaction 6 is countered by its destruction in collisions with the $\mathrm{H}_{2}$ molecules predominant in the plasma (reaction 7). The moderate decrease in the relative concentration of $\mathrm{H}_{3} \mathrm{O}^{+}$observed in Figure 2 for the higher $\mathrm{O}_{2}$ fractions is due to the gradual growth of other ions in the plasma, especially of $\mathrm{H}_{2} \mathrm{O}^{+}$and $\mathrm{O}_{2}^{+}$(not shown for clarity). Specifically, the $\mathrm{O}_{2}{ }^{+}$ion, formed through direct electron impact and with little tendency to protonation, reaches a relative concentration of $\sim 12 \%$ in the ion distribution for the highest $\mathrm{O}_{2}$ fraction.

In order to investigate the simultaneous influence of $\mathrm{NH}_{3}$ and $\mathrm{H}_{2} \mathrm{O}$ in the distribution of protonated ions in the plasmas, we have taken discharges of $\mathrm{H}_{2} /$ air mixtures. The results are shown in Figure 3. As indicated above, the production of $\mathrm{H}_{2} \mathrm{O}$ at the walls is more efficient than 
that of $\mathrm{NH}_{3}$. In the mixtures with air, this higher formation efficiency is compensated by the lower $\mathrm{O}_{2}$ content, and the plasma densities of $\mathrm{H}_{2} \mathrm{O}$ and $\mathrm{NH}_{3}$ are found to be similar (with a slight advantage for $\mathrm{H}_{2} \mathrm{O}$ ). The distributions of protonated ions are always dominated by $\mathrm{NH}_{4}{ }^{+}$, except for the lowest air fraction $(\sim 3 \%)$, where the densities of $\mathrm{H}_{3} \mathrm{O}^{+}$and $\mathrm{NH}_{4}{ }^{+}$are comparable. With growing air content, the proportion of $\mathrm{NH}_{4}{ }^{+}$increases steadily, whereas the relative densities of the other three ions decrease monotonically. The results can be again rationalized in terms of the proton affinities and collision frequencies of the various ions and molecules involved. In these plasmas, the hydronium ion can be formed via reaction 5 but also through collisions of diazenilium $\left(\mathrm{N}_{2} \mathrm{H}^{+}\right)$with water:

$$
\mathrm{N}_{2} \mathrm{H}^{+}+\mathrm{H}_{2} \mathrm{O} \rightarrow \mathrm{H}_{3} \mathrm{O}^{+}+\mathrm{N}_{2} \quad\left(\mathrm{k}=2.60 \times 10^{-9} \mathrm{~cm}^{3} \mathrm{~s}^{-1}\right)
$$

The ammonium ion can now be formed through processes 3 and 4 and also in the reaction of hydronium with ammonia.

$$
\mathrm{H}_{3} \mathrm{O}^{+}+\mathrm{NH}_{3} \rightarrow \mathrm{NH}_{4}^{+}+\mathrm{H}_{2} \mathrm{O} \quad\left(\mathrm{k}=2.23 \times 10^{-9} \mathrm{~cm}^{3} \mathrm{~s}^{-1}\right)
$$

Once more, the direction of the proton transfer in reactions 8 and 9 is dictated by the ordering of the proton affinities of the participating molecules (see Table 1).

The picture of the ion chemistry presented thus far is certainly an oversimplification, since many more species and chemical reactions are involved, but it provides a plausible explanation for the predominance of $\mathrm{NH}_{4}{ }^{+}$in the ion distributions of Figure 3. As soon as the relative densities of the different molecules allow for collisions between the minor plasma species, the various protonated ions can transfer their proton to ammonia and contribute to the production of $\mathrm{NH}_{4}{ }^{+}$. On the other hand, the ammonium ion has no depletion mechanisms (except for wall neutralization) in the plasmas under consideration and, therefore, tends to concentrate in them. The same line of reasoning applies to the rest of the protonated ions in Figure 3. Their relative abundances are largely determined by the number of formation and destruction pathways, which are related to their respective proton affinities, and also by the relative concentration of their neutral precursors. As shown in Figure 3, the lowest relative density corresponds always to $\mathrm{N}_{2} \mathrm{H}^{+}$. In spite of the fact that the proton affinity of $\mathrm{N}_{2}$ is higher than that of $\mathrm{H}_{2}$, the $\mathrm{N}_{2} \mathrm{H}^{+}$ion is efficiently destroyed in collisions with $\mathrm{H}_{2} \mathrm{O}$ and $\mathrm{NH}_{3}$, and the concentration of its neutral precursor, $\mathrm{N}_{2}$, is always much lower than that of $\mathrm{H}_{2}$.

It should be noted that, in most cases, proton transfer processes like those exemplified in the previous paragraphs occur irreversibly on every collision and thus, under many circumstances, a very small amount of a suitable precursor can lead to the predominance of a given protonated ion. Given the very high proton affinity of $\mathrm{NH}_{3}$ as compared with most small molecules (see 
Table 1 and reference [32]), the production of $\mathrm{NH}_{4}{ }^{+}$could represent the final step in the proton transfer chain in many astronomical environments. It can be reasonably argued that the absence of other small molecules and, most notably, carbonated species in the present experiments cast doubts on the suggested predominance of $\mathrm{NH}_{4}{ }^{+}$in some astronomic environments. However, astrochemical models of hot cores that take into account the most relevant carbonated molecules also predict the predominance of $\mathrm{NH}_{4}{ }^{+}$in collapsing protostellar envelopes as soon as a small amount of $\mathrm{NH}_{3}$ evaporated from the grains becomes available (see for instance figure 3 of reference 24 and figure 2 of reference 25). The proton affinities of $\mathrm{CO}, \mathrm{CH}_{4}, \mathrm{CH}_{2} \mathrm{O}$ and $\mathrm{CH}_{3} \mathrm{OH}$ in $\mathrm{kJ} \mathrm{mol}^{-1}$ are 594, 543.5, 712.9 and 754.3 respectively $^{32}$. All of them are lower than that of $\mathrm{NH}_{3}$ and it is expected that if these molecules were present they would lead to results analogous to those represented in Figure 3 of this work, with $\mathrm{NH}_{4}{ }^{+}$as the dominant ionic species. The hydronium ion has indeed been observed in the ISM (see, for instance [33-35] and references therein), but the interstellar detection of the symmetric $\mathrm{NH}_{4}^{+}$remains a challenge to date.

\section{Summary and conclusions}

A study of the ionic chemistry in low pressure cold plasmas, having always $\mathrm{H}_{2}$ as the major component, has been carried out using hollow cathode discharges of different precursor mixtures. Mass spectrometry of neutrals and ions has been employed for the identification of the main chemical species in the plasmas. Specifically, the relative relevance of the protonated ions of various small molecules has been addressed. The ions and processes studied are of interest in the chemistry of the interstellar medium.

Protonated species dominate the ion distributions in plasmas of $\mathrm{H}_{2}$ with small amounts (1$18 \%$ ) of $\mathrm{N}_{2}, \mathrm{O}_{2}$ or air. A chain of proton transfer reactions is found to propagate very efficiently in the direction of the ions with a higher proton affinity. The $\mathrm{H}_{3}{ }^{+}$ion is rarely dominant (only for the highest $\mathrm{H}_{2}$ mixture ratios), but leads rather to the formation of $\mathrm{N}_{2} \mathrm{H}^{+}, \mathrm{H}_{3} \mathrm{O}^{+}$and $\mathrm{NH}_{4}{ }^{+}$. Due to the low proton affinity of $\mathrm{O}_{2}$, only negligible amounts of $\mathrm{HO}_{2}^{+}$are detected in the plasmas. Hydronium and, most specially, $\mathrm{NH}_{4}{ }^{+}$are the most stable ions in the media considered and tend to concentrate most of the positive charge. These laboratory results on cold plasmas support the predictions of some astrochemical models showing that $\mathrm{H}_{3} \mathrm{O}^{+}$and $\mathrm{NH}_{4}{ }^{+}$could be the dominant ions in warm astronomical environments after the evaporation of grain mantels.

\section{Acknowledgments}

This work has been funded by the MICINN of Spain under projects FIS2010-16455 and CSD2009-00038. EC acknowledges funding from the JdC program of the MICINN and MJR acknowledges also a FPI fellowship. We are indebted to M. A. Moreno, D. Pérez and J. Rodríguez for technical support. 


\section{Figure Captions}

Figure 1. Evolution of the relative concentrations of neutral molecules (lower panel) and protonated ions (upper panel) as a function of the initial fraction of $\mathrm{N}_{2}$ in $\mathrm{H}_{2} / \mathrm{N}_{2}$ discharge mixtures. The lines have just been drawn to guide the eye.

Figure 2. Same as figure 1, but for $\mathrm{H}_{2} / \mathrm{O}_{2}$ mixtures.

Figure 3. Same as Figure 1, but for $\mathrm{H}_{2} /$ air mixtures.

\section{References}

[1] Grill A 1993 Cold Plasma in Materials Fabrication (New York: IEEE Press)

[2] Jacob W 1998 Thin Solid Films 3261

[3] Lieberman M A, Lichtenberg A J 2005 Principles of Plasma Discharges and Materials Processing ((New York: John Wiley and Sons Inc.)

[4] Gordillo-Vázquez F J, Herrero V J and Tanarro I 2007 Chem. Vap. Deposition 13267

[5] Martín A, Menéndez A, Pereiro R, Bordel N and Sanz-Medel A 2007 Anal Bioanal Chem. 3881573

[6] Laroussi M 2005 Plasma Process. Polym. 2391

[7] Tabarés F L, Tafalla D, Tanarro I, Herrero V J, Islyaikin A and Maffiotte C 2002 Plasma Phys. Control. Fusion 44 L37

[8] Nakano T, Higashijima S, Kubo H, Yagyu J Arai T, Asakura N and Itami K 2003 J. Nucl. Mat. 313-316 149

[9] Tabarés F L, Rohde V and the Asdex Upgrade Team 2004 Plasma Phys. Control. Fusion 46 B381

[10] Tanarro I, Herrero V J 2011 Plasma Sources Sci Technol. 20024006

[11] Tanarro I, Herrero V J, Carrasco E and Jiménez-Redondo M 2011 Vacuum 851120

[12] Herbst E and Klemperer W 1973 ApJ 185505

[13] Herbst E 2001 Chem. Soc. Rev. 30168

[14] Herbst E 2005 J. Phys. Chem. A 1094017

[15] Petrie S and Bohme D K 2007 Mass Spectrom. Rev. 26 258. See also http://astrochymist ism.html for an update of ions detected in interstellar space.

[16] Agúndez M et al. 2010 A\&A 517 L2

[17] Oka T 2006 Proc Nat. Acad. Sci. 10312235

[18] Geballe T and Oka T 1996 Nature 384, 334

[19] van Dishoeck E F 2006 Proc. Nat. Acad. Sci. 10312249 
[20] Millar T 2005 A\&G 462.29

[21] Giles K, Adams N G and Smith D, 1992 J. Phys. Chem. 967645

[22] Jiménez-Redondo M, Carrasco E, Herrero V J and Tanarro I, 2011 Phys. Chem. Chem. Phys. 139655

[23] Harada N, Herbst E and Wakelam V 2010 A\&A 7211570

[24] Rodgers S D and Charnley S S 2003 ApJ 585355

[25] Aikawa Y et al. 2011, in IAU Symp. 280, The Molecular Universe ed. J. Cernicharo and R. Bachiller, (Cambridge University Press), 33

[26] Carrasco E, Jiménez-Redondo M, Tanarro I and Herrero V J 2011 Phys. Chem. Chem. Phys. 13 19561-72

[27] Castillo M, Méndez I, Islyaikin A M, Herrero V J and Tanarro I 2005 J. Phys. Chem. A $1096255-63$

[28] Méndez I, Gordillo-Vázquez F J, Herrero V J and Tanarro I 2006 J. Phys. Chem. A 110 6060-66

[29] de los Arcos T, Domingo C, Herrero V J, Sanz M M, Schulz A and Tanarro I 1998, J. Phys. Chem. A 1026282

[30] Tanarro I, Sanz M M, Bermejo D, Domingo C and Santos J 1994 J. Chem. Phys. 100238

[31] Anicich V G 1993 J. Phys. Chem. Ref. Data 22 1469. Anicich V G 2003 JPL Publication 2003, 03-19 NASA.

[32] Hunter E P L and Lias S G 1998 J. Phys. Chem. Ref. Data 27413

[33] Wootten A, Mangum J G, Turner B E, Bogey M, Boulanger F, Comes F, Encrenaz P J and Gerin M. 1991 ApJ 380 L79

[34] Goicoechea J R and Cernicharo J 2001 ApJ 554 L213

[35] Yu S, Drouin B J, Pearson J C and Pickett H M 2009 ApJSS 180119 

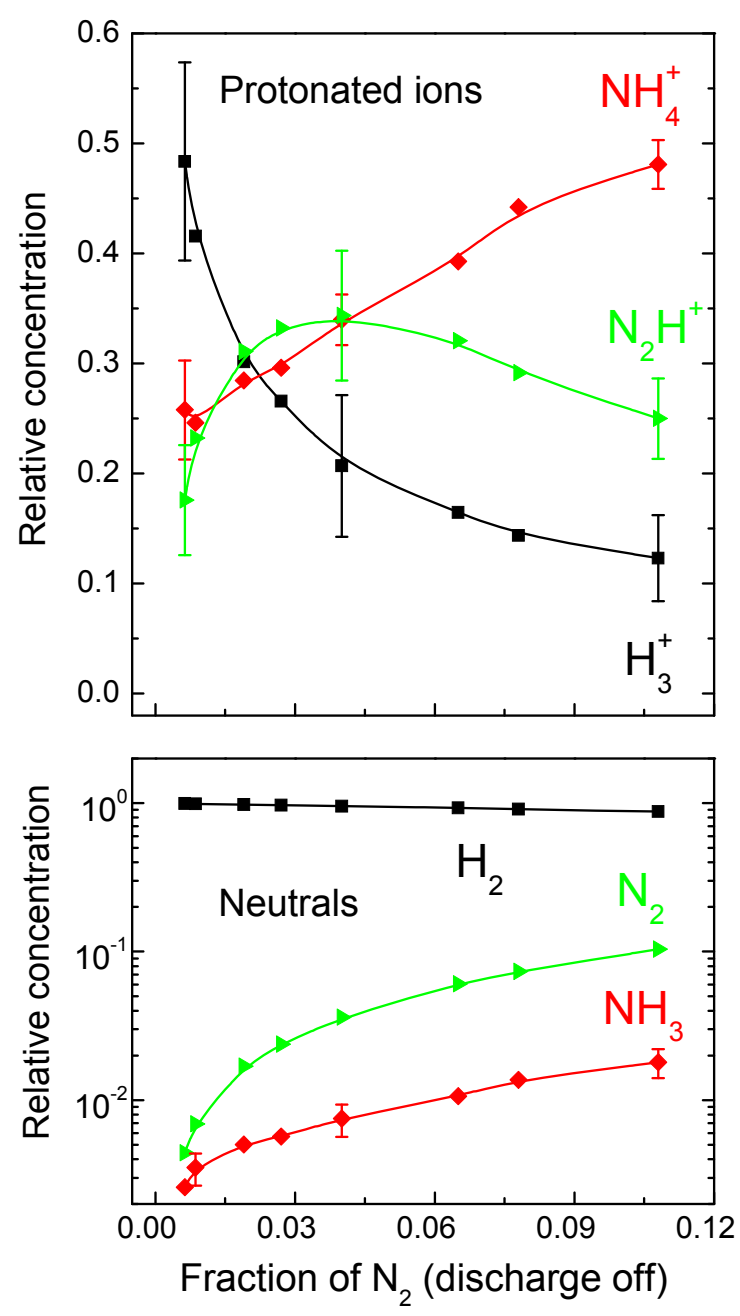

Figure 1 

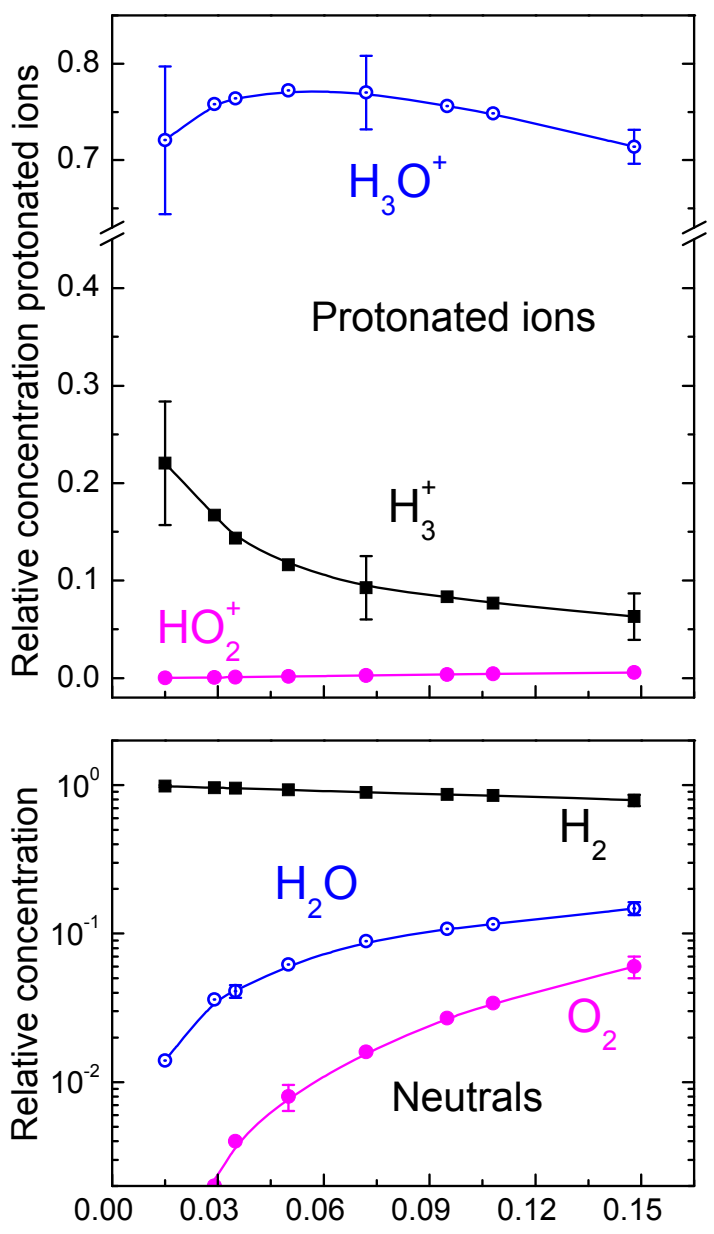

Fraction of $\mathrm{O}_{2}$ (discharge off)

Figure 2 

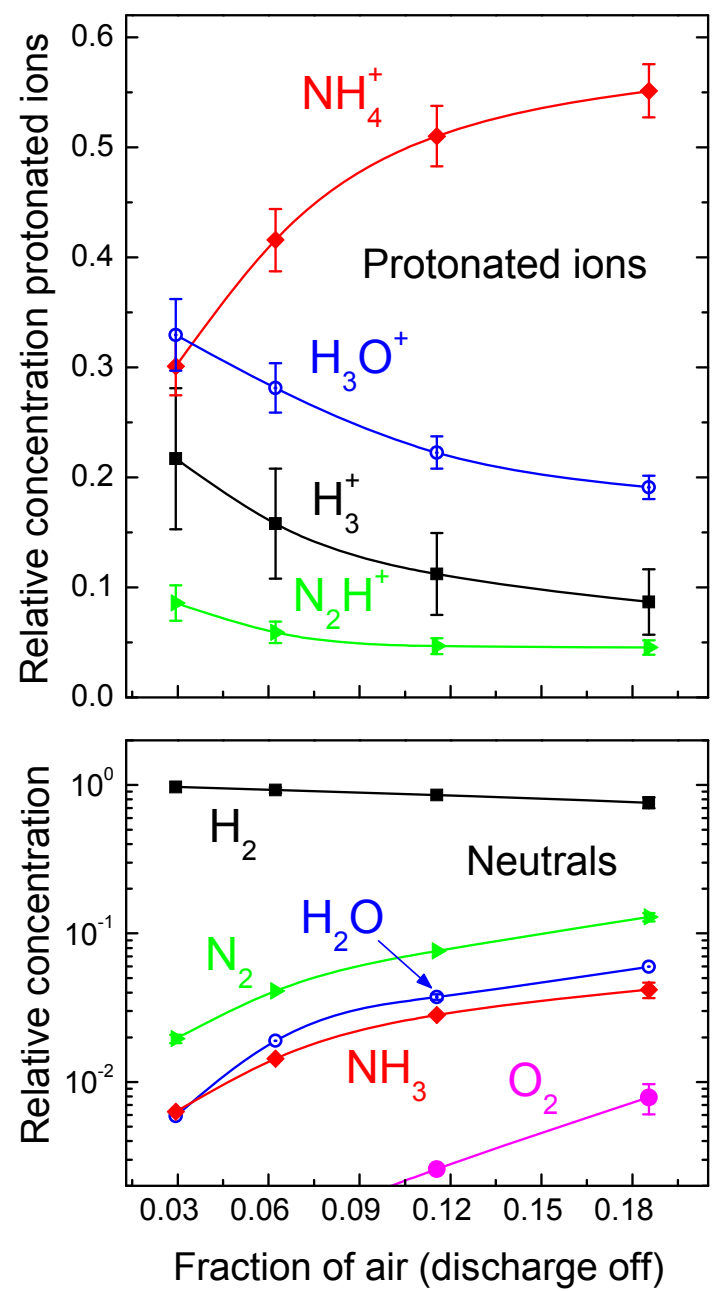

Figure 3 